\title{
A Confutation of the Pessimistic Induction
}

\begin{abstract}
The pessimistic induction holds that successful past scientific theories are completely false, so successful current ones are completely false too. I object that past science did not perform as poorly as the pessimistic induction depicts. A close study on the history of science entitles us to construct an optimistic induction that would neutralize the pessimistic induction. Also, even if past theories were completely false, it does not even inductively follow that the current theories will also come out to be completely false because the current theories are more successful and have better birth qualities than the past theories. Finally, the extra success and better birth qualities justify an anti-induction in favor of the present theories.
\end{abstract}

Keywords: Current Theory, Integrations of Scientific Fields, Past Theory, Pessimistic Induction

Park, Seungbae (2011). "A Confutation of the Pessimistic Induction", Journal for General Philosophy of Science 42 (1): 75-84.

Seungbae Park

Division of General Studies

Ulsan National Institute of Science and Technology

Republic of Korea

nature@unist.ac.kr

\section{Introduction}

According to Putnam (1975), scientific realism (realism henceforth) is the view that a successful theory is approximately true, and that its key term refers. A theory is successful when it has high explanatory, predictive, and manipulative powers. The theory of DNA, for example, has a high manipulative power in that it is widely and effectively used to cure certain diseases and to produce new crops and animals. It follows that it is approximately true, and that DNA exists. If the theory of DNA is completely false, and if DNA is not real, it would be a miracle how the theory is so successfully used in intervening in natural processes.

One of the powerful objections against Putnam's foregoing realism is the pessimistic induction from the history of science that successful current theories are completely false because successful past ones are completely false. In this paper, I 
undertake to refute it with my own observation on the history of science. I argue that a fair study on the history of science reveals that the past science did not perform as poorly as the pessimistic induction depicts, and unveils some important differences between the past and current sciences. On close examination, the pessimistic induction has no persuasive force, although it provided a valuable opportunity to reflect on the structure of past theories and on the differences between past and current theories.

\section{Pessimistic Induction and Realist Responses}

Recall that the pessimistic induction holds that successful past theories are completely false, so successful current theories are completely false too. This formulation of the pessimistic induction would be endorsed by Devitt and Ladyman:

..past scientific theories are not approximately true; so, probably present theories are not approximately true. (Devitt, 2005: 784)

..reflection on the abandonment of theories in the history of science motivates the expectation that our best current scientific theories will themselves be abandoned, and hence what we ought not to assent to them. (Ladyman, 2009)

What is the justification for the premise that successful past theories are completely false? An antirealist would argue that they are completely false because their key terms do not refer. In fact, Laudan says as follows:

To see why, we need to explore briefly one of the connections between 'genuinely referring' and being 'approximately true'. However the latter is understood, I take it that $a$ realist would never want to say that a theory was approximately true if its central theoretical terms failed to refer. If there were nothing like genes, then a genetic theory, no matter how well confirmed it was, would not be approximately true. (Laudan, 1981: 33)

Laudan (1981) is widely believed to have run the pessimistic induction against successful current theories in the philosophy of science literature. To the best of my knowledge, however, he did not even formulate the pessimistic induction, let alone run it against current theories. His real position is rather that there are an overwhelming number of historical counterexamples to the realist inference from success to approximate truth and reference: 
Their epistemology is confronted by anomalies which seem beyond its resources to grapple with. (Laudan, 1981: 47-48)

Note that Laudan claims that there are historical anomalies to the realist inference. I agree with Ladyman (2002: 244) that Laudan's historical claim undermines the realist claim that successful theories are approximately true. Let me point out, however, that Laudan does not go further from his historical assertion, i.e., he does not infer that successful current theories are completely false too. An assertion is not an argument, not to mention an inductive argument. In any event, the target of this paper is the pessimistic induction, not Laudan's assertion.

Worrall's (1989) response to the pessimistic induction is to distinguish between the mathematical structure and theoretical ontology of a successful past theory. $\mathrm{He}$ observes that the mathematical structure was retained through scientific revolutions, but the theoretical ontology was discarded. For example, the mathematical structure of Fresnel's ether theory is enshrined in Maxwell's electromagnetic theory, but the theoretical ontology of the former is replaced by that of the latter. The mathematical structure explains why the theory was successful. Thus, we are entitled to believe that the mathematical structure is true, but we should take a sceptical attitude toward the theoretical ontology of the theory.

Cruse and Papineau (2002) argue that what is preserved across theory change is not mathematical structure but Ramsey sentence. For them, Ramsey sentence is the cognitive content of a scientific theory. It is what we get by replacing the theoretical constants of a scientific theory with distinct variables and then by quantifying over the variables. It is free of theoretical terms, but it contains the structure of the original theory, describing the relations between theoretical entities without committing to what they are. The Ramsey sentence of an old theory is similar to that of the new theory. The approximate truth of the Ramsey sentence explains why a theory is successful, so we are justified to believe "in the approximate truth of a successful theory's Ramsey sentence" (Cruse and Papineau, 2002: 179).

Kitcher (1993: 140-149), Psillos (1996 and 1999, Chapters 5 and 6), and Leplin (1997: 141-152) have a different view on what was carried over in the shift of scientific theories. They argue that working posits of a successful past theory were retained through scientific revolutions, although idle posits were discarded. A working posit is a component of a theory that generates success, and an idle posit is a constituent of a theory that does not do any work in generating success, but makes an ontological commitment on what theoretical entities there are in the world. A working posit of a 
successful past theory explains why the theory is successful, so we are warranted to believe that the working posit is true, but we ought not to believe that an idle posit is true.

The foregoing three positions are different realist responses to the pessimistic induction. They all agree that something is preserved, although they disagree on what that something is, so I shall group them together under the name 'preservative realism.' The debate over the tenability of preservative realism in the literature is interesting, shedding light on what is continuous and discontinuous across theory change, and what theoretical component it is reasonable for us to take a realist attitude on. It is, however, not a concern of this paper to take a stance in this territory. In the following sections, I will rather explore a new territory, hopefully casting light on some interesting differences between past and current sciences. Suffice to say here that preservative realism is compatible with my response to the pessimistic induction.

\section{Critiques of Pessimistic Induction}

\subsection{Optimistic Induction}

Laudan (1981) provides the infamous list of successful past theories which he takes to be completely false. He adds that the list can be extended ad nauseam. Let me quote it here, although long, because it gives us a hint on how to countervail the pessimistic force.

\section{$\underline{\text { Laudan's List }}$}

- the crystalline spheres of ancient and medieval astronomy;

- the humoral theory of medicine;

- the effluvial theory of static electricity;

- "catastrophist" geology, with its commitment to a universal (Noachian) deluge;

- the phlogiston theory of chemistry;

- the caloric theory of heat;

- the vibratory theory of heat;

- the vital force theories of physiology;

- the electromagnetic aether;

- the optical aether;

- the theory of circular inertia;

- theories of spontaneous generation. (Laudan, 1981: 33) 
Note that all the theories on the list were prevalent before the $20^{\text {th }}$ century. None of them was taken to be true in the $20^{\text {th }}$ century.

Does the list show that the central terms of most successful past theories do not refer in the light of the current theories? I say that the answer is no. The list shows at best that the central terms of some successful past theories do not refer. The difference between "some" and "most" is important, for if only some successful past theories are not even approximately true in the light of current theories, realists could construct what I call an optimistic induction, and thereby defeating the pessimistic induction. Suppose that the pessimistic inducer constructs a pessimistic induction with one hundred past theories. In response, the realists could construct an optimistic induction with an equal number of past theories which are considered approximately true in the light of the current theories. The pessimistic force and the optimistic force would cancel out each other. Thus, the pessimistic inference against the current theories would be completely blocked. Notice that constructing the optimistic induction would be impossible, if most successful past theories are not even approximately true.

It is not a hard task to construct the optimistic induction. For any replaced theory on Laudan's list, there is a corresponding replacing theory whose central term refers. For example, for the Ptolemaic theory, there is the Copernican theory, for the phlogiston theory, the oxygen theory, for the caloric theory, the kinetic theory, and so on. The key terms of those replacing theories refer in the light of the current theories. The replacing theories are clearly past theories because there were periods in which they were competing with the replaced ones. So, for example, if the caloric theory is a past theory, so is the kinetic theory.

In his 1981 paper, Laudan claims that the central terms of most successful past theories do not refer in the light of the current theories:

I daresay that for every highly successful theory in the past of science that we now believe to be a genuinely referring theory, one could find half a dozen once successful theories that we now regard as substantially non-referring. (1981: 35)

In his 1984 paper, however, he takes a substantially mitigated attitude toward the history of science in his critical reply to Hardin and Rosenberg (1982). He claims that many successful past theories are completely false:

Yet we now believe that many of those earlier theories profoundly mischaracterize the way the world really is. $(1984: 157)$ 
If only many of the earlier theories were completely false, we are not inductively compelled to believe that successful current theories are not even approximately true.

Let me argue that most central terms of successful past theories refer in the light of present theories. The major theoretical terms of successful theories of the $20^{\text {th }}$ century refer in the light of present theories. Those terms include all the theoretical terms in the periodic table, 'X-ray,' 'electron,' 'proton,' 'neutron,' 'neutrino,' 'Big Bang,' 'black hole,' and 'DNA.' The list of theoretical terms of the $20^{\text {th }}$ century which are still considered to refer can be extended ad nauseam, given that there are numerous theoretical terms in any introductory science text published since the 1990s. So most key terms of successful theories of the $20^{\text {th }}$ century refer in the light of current theories. If most key terms of successful theories of the $20^{\text {th }}$ century refer, then the most central terms of successful past theories refer, even if we grant for the sake of argument that key terms of all successful theories before the 20th century do not refer. The reason is that the body of scientific knowledge exploded in the $20^{\text {th }}$ century with far more human and technological resources. Some historians of science put the explosion of scientific knowledge in the $20^{\text {th }}$ century as follows:

At the end of the $20^{\text {th }}$ century, we've now immersed ourselves in what Newton called the vast sea of knowledge. We've felt and tasted the water. We've washed it over ourselves and what we've learned would astound him and the other great and imaginative minds of generations past. (Brody et al., 1997: 339)

Suppose that we put together the small number of nonreferring theoretical terms before the $20^{\text {th }}$ century and the large number of referring theoretical terms of the $20^{\text {th }}$ century. Most members of the resulting population would refer. An analogy might be useful to make this point clear. Pour a cup of salty water into a lake of fresh water. The resulting water would still be fresh. In short, the past science did better than the pessimistic inducer portrays.

In response, the pessimistic inducer might argue that successful theories of the $20^{\text {th }}$ century are current theories. He might draw a line at the year 1900 to demarcate between past and current sciences. Based on that demarcation, he might construct a new pessimistic induction that most key terms of successful theories before the year 1900 do not refer. Hence, most key terms of successful theories after the year 1900 do not refer as a matter of inductive inference. 
A problem with the pessimistic inducer's possible contention is that the demarcating line, the year 1900, is arbitrary. It is not clear how the pessimistic inducer could transform the arbitrary line into a principled one. Even if he miraculously justifies the line, there still is a problem. If there is such a principled distinction between past and current sciences, then from the fact that the past science performed poorly, it would not even inductively follow that the current science is performing poorly too. Realists might use the pessimistic inducer's justification for the line to protect current science from the bad record of past science. In any case, it would be a grueling task for the pessimistic inducer to draw a non-arbitrary line between past and current sciences without ending up protecting the current science, thereby helping realism.

The predicates 'past theory' and 'present theory' are such a vulnerable spot in the pessimistic induction that the pessimistic inducer might replace them with 'once accepted but no longer accepted theory' and 'currently accepted theory' respectively. 'Current' does not refer to an absolute point of time. It refers to the year in which we run the pessimistic induction. It might be 1920 or 1980 . Now, as long as there are enough theories that were once accepted but no longer accepted at any point of time in the development of science, we can construct a strong pessimistic induction that all the currently accepted theories will be abandoned as all once accepted but no longer accepted theories were.

A problem with the above suggestion is that for any point of time in the development of science there are theories that were once accepted and continue to be accepted. The special theory of relativity belongs to this category in the year 2010. It once was accepted and still is accepted. We can construct an equally strong optimistic induction from such theories to the effect that once accepted theories will remain accepted.

What is Laudan's definition of past theory? He does not have any. He just uses similar phrases: "past theory" (1981: 26), "theory in the past of science" (ibid: 35), and "earlier theories" (1984: 157). It is clear that he does not equate a past theory with a theory that once was accepted but is no longer accepted. It is not the case that for Laudan, only superseded theories are past theories. After all, he (1981) claims that key terms of most successful past theories do not refer in the light of current theories, which allows that key terms of some successful past theories refer in the light of current theories. The successful past theories whose central terms refer in the light current theories might include the Copernican theory, the oxygen theory, and the kinetic theory. They were all developed before the year 1900 . 


\subsection{Extra Success and Neighbor Constraint}

There are two reasons to think that current theories are not going to follow the fate of the superseded theories on Laudan's list. First, the current theories are more successful than their old counterparts. It could be shown that for every successful theory on Laudan's list, there is a corresponding theory we now hold to be approximately true, and that it is more successful than its counterpart on Laudan's list. For example, the plate tectonics theory is more successful than the catastrophic theory, and the kinetic theory of heat than the caloric theory of heat, the oxygen theory than the phlogiston theory, and so on. Some historians put the dramatic difference between the sciences before the $20^{\text {th }}$ century and of the $20^{\text {th }}$ century as follows:

We entered the $20^{\text {th }}$ century riding horses. We will leave it riding spaceships. We entered the century dying of typhoid and smallpox, and will leave it having conquered those diseases. At the turn of the $19^{\text {th }}$ century, organ transplants were unthinkable, while by the turn of this century many will have survived because another person's heart or other vital donated organs sustains them. In 1900 the human life span was 47 years. Today it is 75 . (Brody et al., 1997: 337)

Dopplet (2007) also observes that our best current theories enjoy a higher degree of confirmation than their predecessors:

Our best current theories enjoy a singular degree of empirical confirmation impossible for their predecessors, given their ignorance of so many kinds of phenomena and dimensions of nature discovered by our best current theories. (Dopplet, 2007: 111)

Since the theories of the $20^{\text {th }}$ century and onward are more successful than the theories on Laudan's list, it is wrong to conclude that they are all completely false.

Second, the theories of the $20^{\text {th }}$ century and onward have better birth qualities than the theories before the $20^{\text {th }}$ century. The better birth qualities are due to what I take to be an important revolution in science that occurred at the end of $19^{\text {th }}$ century and the beginning of the $20^{\text {th }}$ century. During this period, various fields of science and special sciences became connected with each other. Biology, for instance, was linked with chemistry at the end of the $19^{\text {th }}$ century when Pasteur finally persuaded the medical community that diseases could be understood in chemical terms (Ashall, 1993: 149). Chemistry was independent of physics up until the early $20^{\text {th }}$ century when Rutherford and Bohr laid the basis for the atomic understanding of chemical bonding (Brody et al., 
1997: 66-78). Some historians of science put what happened to science in the $20^{\text {th }}$ century as follows:

In this century, all the branches and fields of science coalesced into one overlapping, interwoven, intertwined, and interdependent complexity of understanding that is now hurling us into the future. The borderlines that used to clearly separate astronomy, physics, and biology have become fertile fields of common interest and pursuit, together with other fields and subdisciplines... In the $20^{\text {th }}$ century, science became symbiotic and overlapping and scientists no longer desired to maintain their isolation within a defined field. They recognized the need for cross-fertilization - the need to follow developments in the other fields on which they depended and to share information. (Brody et al., 1997: 344)

After the various links were established, scientists of the $20^{\text {th }}$ century and onward, trying to formulate new theories in their fields, have to take into account the theories and the expanded observational data of neighboring fields and sciences. I shall call this phenomenon neighbor constraint. The idea is that different fields of science form an interconnected web and put constraints on each other as to whether a new theory in a field is legitimate or not.

The unification of science that occurred at the end of the $19^{\text {th }}$ century and in the early $20^{\text {th }}$ century seems to have been the driving force that facilitated neighbor constraints. The science of the $20^{\text {th }}$ century and onward gives us a far more unified picture of the world than the science before the $20^{\text {th }}$ century. Up until Copernicus's time, it was believed that there is a fundamental difference between the terrestrial and celestial regions; up until Darwin's time between human beings and non-human organisms; up until Faraday's time between electricity and magnetism; up until Pasteur's time between organisms and non-organisms; and so on. I believe that atomism, which was officially adopted in the early $20^{\text {th }}$ century, added fuel to the unification process. In a disunified science, there is less room for a neighbor constraint. For instance, when Pasteur first claimed that diseases could be understood in chemical terms at the end of the $19^{\text {th }}$ century, medical scientists laughed at him, insisting that organisms are fundamentally different from non-organisms, and that chemists have nothing to say about human physiology. The metaphysical belief associated with the disunified picture of the world prevented chemistry from putting a neighbor constraint on biology.

The concept of neighbor constraint is different from the concept of simplicity. Simplicity is an intrinsic property of a theory, whereas neighbor constraint is not. $\mathrm{T}_{1}$ 
formulated with a neighbor constraint is not necessarily simpler than $T_{2}$ formulated without one. Let me take current geology and catastrophist geology on Laudan's list as examples. Geologists today use the radiometric dating technique, the method to determine the ages of materials, when they formulate a theory about distant past events. The technique was developed at the end of the $19^{\text {th }}$ century by physicists who were investigating the phenomena of radioactive decay. Catastrophists, on the other hand, did not take the dating technique into account. Catastrophist geology, which was developed before the $19^{\text {th }}$ century, postulated the existence of Noachian deluge to explain marine fossils in mountain ranges. Now, current geology might be simpler than catastrophist geology. But if so, that needs to be argued for independently of the fact that it took the dating method into account whereas catastrophist geology did not.

What is a condition under which $\mathrm{T}_{1}$ puts a neighbor constraint on $\mathrm{T}_{2}$ ? An answer to this question can be found in the examination of the relationship between the plate tectonics theory and the electromagnetic theory. A piece of evidence for the plate tectonics theory is the parallel strips of rock with alternating magnetic direction discovered on the ocean floor in the 1950s. The explanation of the strips of rock was that the molten rock containing iron oxides continuously erupted through fissures on the ocean in the past. Iron oxides oriented themselves in accordance with the magnetic field of the earth while the rock was in the fluid state. As the sea floor moved away from the fissures, the fluid rock solidified and the direction of the iron oxides in it was fixed. Scientists knew in the 1950s that the magnetic field of the earth changed direction sporadically over time, so they thought that the direction of the iron oxides in the molten lava changed with the reversal of the magnetic field, and that it became fixed as the sea floor moved away from the fissures. In short, the continuous eruptions of lava, the reversals of the magnetic field, and the motion of the sea floor jointly produced the strips of rock with alternating magnetic direction. Notice that scientists took the electromagnetic theory into account when they came up with the hypothesis that the sea floor moved away from the fissures. Now, if the plate tectonics theory were disproved, the electromagnetic theory cannot explain why there are parallel strips of rock with alternating magnetic direction on the ocean floor. In other words, if the plate tectonics theory were refuted, the electromagnetic theory suffers from the anomaly, the strips of rock. It follows that $T_{1}$ imposes a neighbor constraint on $T_{2}$ when the rebuttal of $T_{2}$ gives rise to an anomaly to $\mathrm{T}_{1}$.

What is the reason for thinking that neighbor constraint confers evidential support on a newly born theory? In other words, why is it that a theory born with neighbor constraint is more likely to be true than a theory without it? An answer to this question 
can be derived from the consideration on underdetermination. Suppose that there are three rival theories in a certain domain. They make incompatible claims about unobservable parts of the world, but each of them is compatible with all the available evidence. One scientist randomly chooses one from the three theories and believes that it is true. Another scientist, however, knows that one of them conflicts with a neighboring theory which was previously confirmed, so he sets it outside the range of his choice, chooses one from the remaining two theories, and believes that it is true. In such a situation, the second scientist's belief has a higher probability to be true than the first scientist's belief, although we may not know whose belief is true. This example shows that a neighboring theory has the function of eliminating a false theory from a set of competing theories, thereby increasing the probability that a newly constructed theory is true.

What can we conclude from the fact that the theories of the $20^{\text {th }}$ century and onward are more successful and have better birth qualities than theories from before the $20^{\text {th }}$ century? We can conclude, firstly, that the pessimistic induction is problematic. An additional premise is required for the pessimistic inducer to infer from (1) to (2):

(1) Successful theories before the $20^{\text {th }}$ century are completely false.

(2) Successful theories of the $20^{\text {th }}$ century and onward are completely false.

The additional premise is that extra success and neighbor constraints do not provide any evidential support for the theories of the $20^{\text {th }}$ century and onward. Unless the additional premise is justified, the inference from (1) to (2) is unwarranted. The pessimistic inducer, however, is fully committed to the reliability of induction. After all, if the reliability of induction is suspect, the pessimistic induction cannot even get off the ground. But if induction is a reliable rule of inference, extra success and neighbor constraints should be taken to have evidential support for the theories of the $20^{\text {th }}$ century and onward. So the pessimistic inducer cannot even in principle prove that the additional premise is true.

We can conclude, secondly, that the pessimistic induction is a fallacy of biased statistics. The pessimistic inducer took samples only from science before the $20^{\text {th }}$ century. Recall that Laudan's infamous list consists of twelve successful theories all of which were prevalent before the year 1900. The minimum requirement for fair samples is that they be randomly selected from the sciences of both before and after the year 1900. Laudan's samples do not meet this requirement. Moreover, if the samples were fairly chosen, most of the samples would be theories of the $20^{\text {th }}$ century, the reason 
being that scientific knowledge exploded in the $20^{\text {th }}$ century. If most samples are taken from the science of the $20^{\text {th }}$ century, most key terms of the samples would refer in the light of present theories as argued earlier.

Thirdly, with the extra success and neighbor constraints, I am inclined to run an anti-induction in favor of the theories of the $20^{\text {th }}$ century and onward. Scientists made mistakes in the past, and thereby learning lessons from them, so they must be close to truths now. Thus, the superseded theories on Laudan's list are the positive evidence for the approximate truths of the current theories. The larger the list is, the better evidence it is that the present theories are approximately true. Humans are different from inanimate objects like stone. As for a stone, the future resembles the past. When thrown upwards, it fell down and will continue to fall down. As for humans, however, the future differs from the past. They fell down but learned to fly by using airplanes.

\section{Conclusion}

There are a few problems with the pessimistic induction. First, given that the amount of scientific knowledge exploded in the $20^{\text {th }}$ century, we are justified to believe that most key terms of successful past theories refer in the light of successful current theories. Second, successful theories of the $20^{\text {th }}$ century and onward are more successful and have better birth qualities than their counterparts before the $20^{\text {th }}$ century, so the inductive inference from the failure of the latter to that of the former is unwarranted. Thirdly, the extra success and better birth qualities justify an anti-induction that since successful theories before the $20^{\text {th }}$ century were completely false, successful theories of the $20^{\text {th }}$ century and onward are approximately true. Humans learn lessons from past mistakes and improve themselves, so their past and future are not uniform. The uniformity principle is not applicable to every aspect of humans.

\section{References}

Ashall, F. (1994). Remarkable Discoveries! New York: Cambridge University Press.

Brody, E. and Brody, A. (1997). The Science Class You Wish You Had...: The Seven Greatest Scientific Discoveries in History of Science and the People Who Made Them. New York: The Berkeley Publishing Group.

Cruse, P., and David Papineau (2002). "Scientific Realism without Reference", in Michelle Marsonet (ed.). The Problem of Realism. Aldershot, U.K.: Ashgate. 
Devitt, M. (2005). “Scientific Realism”, In The Oxford handbook of Contemporary Analytic Philosophy. Frank Jackson and Michael Smith, (eds.) Oxford: Oxford University Press, 767-791.

Doppelt, G. (2007). "Reconstructing Scientific Realism to Rebut the Pessimistic Metainduction", Philosophy of Science, vol. 74, 96-118.

Hardin, C., and A. Rosenberg, (1982). "In Defense of Convergent Realism”, Philosophy of Science, vol. 49, 604-615.

Kitcher, P. (1993). The Advancement of Science. New York: Oxford University Press.

Ladyman, J. (2002). Understanding Philosophy of Science. London: Routledge.

---------. (2009). “Structural Realism”, Stanford Encyclopaedia of Philosophy.

Laudan, L. (1981). “A Confutation of Convergent Realism”, Philosophy of Science, vol. $49,19-49$.

(1984). "Discussion: Realism without the Real”, Philosophy of Science, vol. 51, 156-162.

Leplin, J. (1997). A Novel Defense of Scientific Realism. New York: Oxford University Press.

Psillos, S. (1996). "Scientific Realism and the Pessimistic Induction", Philosophy of Science (Proceedings), S306-S314. (1999). Scientific Realism: How science tracks truth. New York: Routledge.

Putnam, H. (1975). "Realism in Mathematics and Elsewhere", Philosophical Papers vol. 1., Cambridge University Press.

Worrall, J. (1989). "Structural Realism: The Best of Both Worlds", Dialectica, vol. 43, 99-124. 
